\title{
THERAPEUTIC USE OF SODIUM CHLORIDE IN INDUSTRY
}

\author{
BY \\ DONALD STEWART
}

Birmingham

Many thousands of industrial workers are subjected to heat by reason of their occupation; for example, non-ferrous metal casters, forge hammer workers (stampers), iron and steel foundry workers, furnacemen and stokers, glass-blowers, heat-treatment operators, lime-kiln workers, shake-house workers and miners. But a much greater number of workers can have their comfort and efficiency temporarily interfered with not because they work on hot processes but because of sweating in hot weather and heat waves, more particularly in those factories where ventilation is poor, or where it may be inadequate because of black-out conditions. Sweat contains sodium chloride in varying amounts, and under ordinary circumstances its loss through this secretion is not significant. But under conditions which cause profuse sweating the unregulated loss of salt in the large amount of water given off as sweat may seriously deplete the supply in the body. The use of sodium chloride in the prevention of discomfort, ill-health and absenteeism due to excessive heat during the summer months is therefore a matter of importance, in the same way that its administration is known to be specific in the prevention of heat cramps and collapse associated with hot processes.

\section{Body Heat Regulation}

According to Howell (1940) the nervous mechanisms which are immediately concerned with heat loss or heat production do not act independently but are co-ordinated with reference to changing conditions so as to maintain a constant body temperature.

Heat is regularly lost from the human body under normal conditions in a number of ways as follows:

1. Through the urine, faeces, saliva, which are at the temperature of the body when voided.

2. Through the expired air, which is warmer than the inspired air and is nearly saturated with water vapour. The vaporization of water requires heat which is taken from the body supply.

3. By evaporation of water from the skin.

4. By radiation of heat from the skin.

5. By convection or conduction, that is by heating the air in contact with the skin.

\section{Loss of Heat by Sweating in Relation to Working} Conditions

Among industrial workers the relative importance of these methods of heat loss will vary with conditions at the place of work. For example, high external temperatures will tend to diminish the loss from radiation, while increasing that from evaporation owing to the greater production and more rapid evaporation of sweat. It has been estimated by Dubois and Hardy, reported by Howell (1940), that under experimental con- ditions in the laboratory with external temperatures of $70^{\circ}-80^{\circ} \mathrm{F}$., loss by radiation constitutes $60-65$ per cent. of the total, and the loss by evaporation about 20-30 per cent. But at temperatures of $90^{\circ}-95^{\circ} \mathrm{F}$. radiation and convection drop out and heat loss is affected only through vaporization. On heat-producing processes and in hot weather excessive sweating at work is common, the degree varying with the occupation and its physical requirements and with the individual. Sedentary workers rarely begin to sweat at temperatures below $88^{\circ} \mathrm{F}$., but where heavy physical effort is required sweating begins at lower temperatures. Where temperatures of $80^{\circ} \mathrm{F}$. occur, rising as they may do to $90^{\circ}$ and even $100^{\circ}$, or more, sweating becomes one of the main ways by which the individual loses heat. Drinker (1936) points out that with external temperatures of $95^{\circ}-120^{\circ} \mathrm{F}$. the amount of sweat produced at ordinary work may be as high as 7.5 litres per day. With a chloride concentration in the sweat of, say, 0.3 per cent. this would mean a loss of $22.5 \mathrm{~g}$. of salt. Since the average normal excretion of salt in the urine is about $12 \mathrm{~g}$. in 24 hours, the degree to which work in heat may deplete body chlorides is clear.

The relation of humidity * is important. If the air is already saturated, sweat is not evaporated and runs off the body with little effect on heat loss. According to Baetjer (1943) at high temperatures a low relative humidity is therefore essential for heat loss, but high humidity greatly increases the harmful effects of heat. There is therefore a vital relationship between the incidence of symptoms and ventilation.

Air movement if adequate does much to create comfort at work. It increases heat loss by exchanging the warm moist layer in contact with the skin with cooler drier air, but if the air temperature is higher than the body temperature and the air is saturated, air movement is of no value in increasing heat loss.

\section{Chloride Intake}

It is generally accepted that the sodium chloride intake should normally be a minimum of 3-4 g. per day (Howell, 1940). With ordinary diets the intake may range between 10 and $20 \mathrm{~g}$. per day, most of it in seasoning, but its reduction to $5 \mathrm{~g}$. or even 1 or $2 \mathrm{~g}$. is said to cause no disturbance (Sollman, 1939). Sodium chloride constitutes the greater part of the electrolytes of the tissues and fluids of vertebrates, and its ions are essential for the maintenance of life. These ions are constantly replenished because of the instinctive use of salt in food. According to Sollman the entire body contains about 0.17 per cent. sodium chloride; of this about one-third is in the skin, the remainder chiefly in the blood, muscles, bones and intestines.

\section{Chemical Composition of Sweat}

The exact chemical composition of the sweat is difficult to determine because it is so frequently mixed with sebaceous secretion. The reaction is usually acid, the $p \mathrm{H}$ averaging $5 \cdot 65$. The chief salt is sodium chloride in a concentration of $0.5-0.6$ per cent. Moss (1923)

* The relative humidity of the air is the amount of water vapour present in the air at any given time expressed as a percentage of the maximum amount which the air could hold at the same temperature and pressure. 
states that the chlorides are 60 per cent. sodium, 40 per cent. potassium. Although the amount of chloride in the sweat is in general less than in the blood, it would seem that its excretion by the sweat is unregulated, in the sense that there is no control threshold value such as exists in the case of urine (Howell, 1940). Normally chlorides are excreted mainly by the urine and only a small part by the faeces and skin, but rises in temperature to $80^{\circ}$ and $90^{\circ} \mathrm{F}$. greatly increase the loss by the skin until it becomes the main medium of chloride excretion.

\section{Clinical Effects of Excessive Heat}

There comes a stage when loss of heat produces in certain groups of workers-particularly those over 50 years of age - clinical signs and symptoms by way of warning such as sweat, thirst, change in taste, headache and fatigue. If the loss is maintained by continued sweating the sense of fatigue becomes greater, vomiting may start, the body temperature rises, cramps of the legs and abdomen develop suddenly and increase in severity, and eventually the man will collapse. This syndrome has been observed during the past 12 years in some 50 cases among non-ferrous metal casters, stampers and forge workers, iron and steel foundry workers, and furnacemen and stokers, especially in hot weather. A simple clinical classification would include three distinct types of ' heat disease' in industry in this country: (1) heat fatigue; (2) heat cramp; (3) heat collapse. These correspond closely to the classificaation of Heilman and Montgomery (1936), Johnstone (1942), Baetjer (1943) and other observers. Heat fatigue and heat cramp occur most commonly in occupations where preventive measures are not taken; they can be clearly differentiated, although cramps are frequently accompanied by fatigue or exhaustion.

(1) Heat Fatigue. This occurs invariably in the summer months on the rare occasions when the weather is really hot. Workers on processes where heat is given off are more liable to be affected. Increase of atmosphere humidity and diminished air movement in the factory are important causal factors. The condition is commonly found among girls. In hot weather girls frequently complain as groups rather than as individuals, so there is also a potential psychological factor in causation.

On a hot day in the summer of 1943 four girls engaged in the manufacture of scientific glass, but not working near to each other, went to the factory ambulance room suffering from heat fatigue. In an hour the whole shop of some 30 girls became ' affected' in what might almost be termed epidemic form. While the four original cases conformed to the clinical syndrome, the majority of the remainder had symptoms so variable that it was difficult to include them in any known physical classification. It appears therefore that they suffered from a ' group neurosis' - not an uncommon entity in industry, and one closely related to the phenomena of unrest in groups of workers. Amongst remedies suggested were better ventilation by increasing air movement; shortening hours of work temporarily; and regular issue of saline drinks (v.i.).

There has been no recurrence since that time.

The clinical features of heat fatigue are: sweating (this is usually early), thirst, mild headache and a developing fatigue. The patient becomes irritable, girls may cry easily or show other signs of a mild emotional state. In a number of cases the temperature is slightly raised, but the pulse rate is normal. On examination no specific physical signs can be observed.

(2) Heat Cramp. The clinical picture of this entity in industry is well known and has recently been described by Johnstone (1942) and Baetjer (1943). Symptoms include all those found in heat fatigue, plus the specific feature of cramp which may occur in the legs but more commonly in the abdominal muscles. One further important diagnostic point is the type of occupation in which the man was at the time of onset.

(3) Heat Collapse. This is not common in industry in this country. Only two cases have been observed. Both were elderly men working as stokers in a confined space where ventilation was inadequate, and during a hot summer. In each case the body temperature was over $103^{\circ} \mathrm{F}$. The primary diagnostic point was the occupation of the men.

\section{Administration of Sodium Chloride}

As a Preventive Measure. It has been shown that profuse sweating is accompanied by salt depletion in the body and the prevention of heat exhaustion consists mainly in the ingestion of sufficient salt and replacement of the fluid loss. There is no evidence that glucose should also be used (Sievers, 1943; Pitts et al., 1944), and Pitts and his colleagues were unable to detect any advantage from administering ascorbic acid, thyamine hydrochloride, riboflavin, or brewer's yeast. The classical work of Haldane $(1916,1929)$ and Moss $(1923,1924)$ in connexion with the mining industry, as well as the later accounts of Talbott and others (1937), clearly show the value of salt in preventing fatigue and collapse among hot process workers.*

A main difficulty in finding a suitable preparation was that of taste, and many attempts were made before finally deciding on one both palatable and physiologically correct. According to Dill and others (1936) steel companies in the U.S.A. find that 0.1 per cent. of solution of sodium chloride cooled to $46^{\circ} \mathrm{F}$. is agreeable to their workers. A series of experiments with different types of salt drinks in different concentrations was therefore carried out in a large group of foundry workers. It was found that salt with lemon or other flavouring, or salt and oatmeal in water, was not always palatable, and that the giving of pure sodium chloride tablets was frequently associated with nausea unless large amounts of water were given as well. Ordinary water in excess did little to help; it can be actually harmful as it increases water and chloride loss. For the same

* Recent experiments by Pitts and his colleagues (1944) show that the best performance of fully acclimatized young men on a good daily diet, performing intermittent hard work in the heat, is achieved by replacing hour by hour the water lostin swe exhaustion. Replacewater leads to ins in the sweat hour by hour had no demonstrable ment of the salt lost advantage; the authors point adequate salt in their dis. drink as much water as they sweat, and that at work never voluntarice of the diet being deficient in salt. "Under there is always the chance of conclude, "it is highly desirable to ensure ach circumstances, the salt, by means of salted drinking water or tablets." 
reason large amounts of beer, still frequently taken by foundry workers and metal casters, is a measure to be condemned; it has been stated (Baetjer, 1943) that more heat cases can be expected among workmen who are addicted to excessive consumption of alcoholic drinks.

It was finally decided that a tablet with the following ingredients was the most palatable:

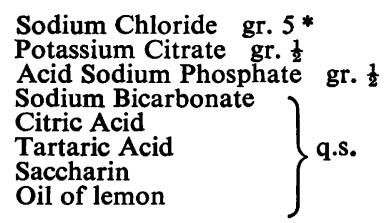

The different ingredients, other than sodium chloride, have purely a dispensing value in the manufacturing process. Each of these tablets when dissolved in $\frac{1}{2}$ pint of water makes a pleasant drink with an approximate concentration of 0.1 per cent. sodium chloride. $\dagger$ In the great majority of workers on hot processes one to three pints of this mixture per shift will entirely prevent the onset of unpleasant symptoms; if symptoms do occur this frequently removes them in the most dramatic way. Some workers like to suck the tablets in the mouth, but dilution in water is always necessary because of the need for fluid replacement. $\ddagger$

In the prevention of heat symptoms the basic importance of improving working conditions must be emphasized, and it should be remembered that the physical fitness of the worker and the type of clothing he wears are additional factors in determining the onset of symptoms. Saline drinks are only a palliative and where possible the cause of excessive heat at work should be removed. One of the difficulties during war-time has been the provision of adequate ventilation because of black-out regulations. In the U.S.S.R. Starkov and Jikesh (1935) studied the reactions of a group of workers in hot industries and the first remedy they suggest is improvement of working conditions; this included the introduction of water-screens and forced ventilation, provision of adequate rest periods, training of new workers, and pre-engagement medical examinations.

Treatment. Talbott and others (1937) advise at least 2 litres of normal saline solution intravenously in cases of heat collapse. When swallowing is impossible or difficult intravenous injection must be the method of choice, but not in the industrial medical departments in this country; such cases must become the responsibility of the hospital physician. In hot climates, and especially in the tropics, either

\footnotetext{
* While tablets containing $7 \frac{1}{2}$ or 10 grains $\mathrm{NaCl}$ are equally palatable there are manufacturing difficulties where the amount is over 5 grains. In concentrations over 0.2 per cent. (10 grains/half-pint) sait is noticable in the mixture, which then becomes unpalatable. annually.

\pm It has been suggested by Pether (1944), after observation of this problem in the Middle East with the problem in the Middle East with the R.A.M.C., that potassium described by Oswald (1925) the salt mixture; and the saline drink contained 2 parts of potassium chloride for every a large gas works, chloride, 2 parts of potassium chloride for every 3 parts of sodium Further work on this point may therefore be necessary.
}

on land or at sea, adequate provision has to be made at the place of work for immediate therapy if life is to be saved.

Other therapeutic measures used in the U.S.A. have been adrenaline, calcium gluconate, glucose (10-50 per cent.), nitrites and calcium chloride (10 per cent.), sodium bicarbonate ( 3 per cent.), but in the experience of Drinker (1936) and others no one of these has been successful.

Heat cramps of the most severe type are rare, but treatment in the factory should consist of the administration of 0.4 per cent. saline by the mouth (4 tablets in $\frac{1}{2}$ pint of water). These cases must always be referred direct to hospital in the same way as a serious injury, and be given similar general treatment.

Mild heat cramps are treated by Talbott by the ingestion of 2-3 litres of 0.5 per cent. salt solution, and in his view such cases need not be sent to hospital. Moderate and mild cases, and cases of heat fatigue, rapidly improve with $\frac{1}{2}-2$ pints of the 0.4 per cent. mixture prepared for the severe cases. An hour's rest in the factory ambulance room usually cures the condition, but even in cases that are mild it may be advisable to prohibit work for the rest of the shift.

\section{Summary}

Excessive sweat is accompanied by abnormal loss of sodium chloride through the skin. Fluid replacement is necessary and should include sufficient sodium chloride, otherwise the individual will suffer from fatigue, cramp, or collapse.

In industry symptoms due to heat occur mainly among elderly workers on hot processes where extensive physical effort is required.

In heat waves any worker can be affected so the need is stressed for adequate ventilation of departments and shops where hot processes are worked, and for better general factory ventilation, with special reference to the promotion of air movement and humidity control.

A suitable preparation of sodium chloride in tablet form is described. One tablet contains $0.3 \mathrm{~g}$. ( 5 grains) of sodium chloride, and when dissolved in $\frac{1}{2}$ pint of water makes a palatable drink. After extensive trial this has proved satisfactory in the prevention of fatigue and other symptoms due to excessive heat.

\section{REFERENCES} Baetjer, A. M. (1943). In Wampler's Principles and Practice of Dill, D. B., et al. (1936). J. industr. Hyg., 18, 417.

Dill, D. B., et al. (1936). J. industr. Hyg.,
Drinker, C. K. (1936). Ibid., 18, 471.
Haldane, J. S. (1916). J. Physiol., 50, 609.

Haldane, J. S. (1916). J. Physiol., 50, 609. 43

Heilman. $\mathrm{M}$. W

Howell, E. H. (1940). Textbook of Physiology, 14th ed., W. B. Howell, E. H. (1940). Textbook of Physiology, 14th ed., W. B.
Saunders Company, Philadelphia and London; pp. 875, 967. Johnstone, R. T. (1942). Occupational Diseases, W. B. Saunders Company; p. 465 .

Moss, K. N. (1923). Proc. roy. Soc., B, 95, 181.

(1924). Trans. Inst. min. Engs., 66, 284.

National Research Council, U.S.A.' (1941). Fatigue of Workers,

Reinhold, N.Y.; p. 23.
Oswald, R. J. W. (1925). Lancet, 1, 1369.

Pether, C. G. (1944). Personal communication

Pitts, G. C., et al. (1944). Amer. J. Physiol., 142, 253.

Sievers, R. A. (1943). In Gafafer's Manual of Industrial Hygiene, W. B. Saunders Company; p. 820 .

Sollman, T. (1939). Manual of Pharmacology, "5th ed., W, B. Saunders Company; p. 820

Starkov, P. M., and Jikesh, J. V. (1935). J. industr. Hyg., 17, 247.

Talbott, J. H., et al. (1937). Ibid., 19, 258. 